supporting services in the community were discussed, e.g. social service provisions (day centres, hostels, special services for the elderly, accommodation at all levels of dependence) or alcohol treatment agencies. In three quarters of the interviews relatives asked how they could help the patient or manage the problem. This led to discussions on interpersonal relationships, behaviour, preventative measures, etc. The relatives' own needs and emotions were prominent-guilt or anger when demented patients were admitted or discharged, or when the supply of alcohol to housebound patients was discussed. Other matters frequently raised were arranging and evaluating ECT and interpreting medical or surgical investigations and treatments. Legal matters discussed included injunctions, access and custody of children, court of protection and many aspects of the Mental Health Act.

Similar information was obtained from non-relatives, e.g. friends, neighbours and staff of old folks homes. These interviews are not included nor are the many other interviews with relatives held by other members of the team. Relatives seem to want guidance on management, information about ancillary services, but not diagnoses. Relatives have usually spent more time observing the patient than the doctor has, know what is 'normal' for the patient and may pick up early or subtle changes for the worse or better, before they are apparent to the doctor. These views must be listened to. The doctor should always ensure he is treating the appropriate person!

Clatterbridge Hospital

M. T. MALCOLM

Bebington, Wirral

\section{ECT on OPD basis}

\section{DEAR SIRS}

I was pleased to read Dr Anvil V. Shah's letter (BulletinSeptember, 1986, 10, 248) in which he discusses modified ECT given on an out-patient basis. His reason for doing it is the same as mine since 1945 when I was working at the Psychiatric Department of the Pazmany Peter University in Budapest. My feeling was that I had no right to admit patients, only because they were depressed, to a psychiatric ward and exclude them from their family support and home environment. I remember my first OPD treatment in 1945 of a 35 year-old female patient whose husband did not return from concentration camp. I thought she had been punished enough not to be locked up among more severe cases. Her sister came along with her for each treatment and looked after her until she recovered.

I also administered Pentothal for anaesthesia, as prior to 1942 the ECT was carried out without anaesthetics.

Since 1966 I have given modified ECT whenever I could count on the family's support. In 1974 I have established a day clinic, where cases of endogenous depression, schizophrenia, patients are receiving treatment, in florid cases two to three times a week, then in chronic cases as follow-up, once a week, then in two weeks.
Because the interior of the clinic looks like a pleasant art gallery and has little resemblance to the old fashioned surgeries or hospitals, patients are coming back of their own volition when they have recurrent symptoms.

May I also emphasise that one has to be sure of the right indications and be careful of complications; I am always on the premises and also this way no stigma attaches to the patients. They stay with the family and go back to work as soon as they recover from the acute state. And last, but not least, there is a cost saving for the government because no hospital bed is required for 24 hours, which is the most expensive part of most of the medical services.

William Osler Hall

IMRE ZADOR

6 Wellington Street

Woollahra, NSW, Australia

\section{Hospital beds for psychiatric patients}

\section{Dear Sirs}

I am sure that Professor Priest's letter 'Hospital Beds for Psychiatric Patients' (Bulletin, November 1986, 10, 322-323) was a well intentioned attempt to assist psychiatric planners to obtain more resources. However I was dismayed that he should attempt to provide figures for bed norms without relating them to other parts of the service. There are alternatives for the treatment of even seriously ill psychiatric patients. The need for in-patient beds will vary with the availability of these alternatives as well as with local psychiatric morbidity. By continuing to concentrate on bed norms in isolation Professor Priest encourages the tradition of a 'bed led' service. He then goes one step further and suggests that $30 \%$ of these beds should be empty! I do not think this approach is much help in the planning of a comprehensive service. It inevitably leads to the relative impoverishment of community resources which might offer more appropriate responses to the needs of patients.

\section{Barnsley Hall Hospital}

D. MCGOVERN

\section{Bromsgrove}

\section{Dear Sirs}

Dr McGovern points out that there are alternatives to a hospital bed for the treatment of even seriously ill psychiatric patients. I accept that in theory, and in places, this is so, and most of us are following with interest experiments that offer a radical alternative to the traditional pattern of care.

However that was not the issue that my letter entitled 'Hospital Beds for Psychiatric Patients' was intended to deal with. The problem faced by many of our members, in trying to plan for mental health services, is that in their conversations with administrators the general rules are not clear. My letter was intended to throw some light on that. Because my letter was welcomed by the Regional Advisers-to whom it was sent in the first place-it was suggested that it might have a wider reading. 
It was certainly not an attempt to offer a formula for 'a comprehensive service'. Still less was it intended to set the pattern of mental health care in tablets of stone. I hope, though, that members may find it useful as establishing a starting point for discussion. If, for instance, their local administrators accepted such norms, with qualification, for a 'bed-led' service, then they might be sympathetic to alternatives which would cost less, or at least no more. Unfortunately many of our members find their existing resources are whittled away to very unsatisfactory levels. It is not easy for them to defend themselves unless they can quote figures. Dr McGovern is right in supposing that my letter was well intentioned, but not necessarily to assist psychiatric planners to 'obtain more resources'-sometimes to help them to avoid losing what they have at present. I fully accept that any discussion of bed norms must be hedged around with many qualifications before being translated into beds.

R. G. Priest Registrar

\section{Consultant psychiatrist in mental handicap DeAr SIRS}

I read the article 'The Role of the Consultant Psychiatrist in Mental Handicap' by Caroline Marriott (Bulletin, December 1986, 10, 347-348) with much interest.

Dr Marriott seems to support the view that the Consultant Psychiatrist in Mental Handicap should take a full share of all services for the mentally handicappedalbeit endorsed by the DHSS (NI) in 1978. I feel that, for far too long, services for the mentally handicapped have been unsatisfactory because of the concept of the Consultant in Mental Handicap, dealing with mental to dental problems of the mentally handicapped.

The admission of a large number of mentally handicapped people (irrespective of their needs) to hospitals for the mentally handicapped aided and abetted this concept. As a direct result of this, other medical specialists and General Practitioners got used to the idea that any medical problem should be dealt with by the Consultant in Mental Handicap.

The role of Consultant in Mental Handicap has crystallised at last and most Consultants would prefer to call themselves Consultant Psychiatrist in Mental Handicap, which has the blessing of the Royal College of Psychiatrists as well.

The Consultant Psychiatrist in Mental Handicap should practise psychiatry and leave non-psychiatric medical problems to generic services. In fact, Dr Marriott mentions that "Consultants in Mental Handicap must work closely with all other medical and non-medical professionals likely to be in contact with mentally handicapped people."

But the initiative of disengaging from non-psychiatric problems and making other medical specialists and General Practitioners interested and involved in the problems of the mentally handicapped must come from Psychiatrists in Mental Handicap. It is easier said than done but can be achieved with energy, enthusiasm and persuasion and, most importantly, by face to face approaches to all the people concerned, as many medical specialists of different disciplines and General Practitioners need education, re-orientation and reassurance in order to deal with the problems of people with mental handicap.

With the rotation of junior psychiatric posts in Psychiatry of Mental Handicap, in the course of time General Psychiatrists should be able to cope with the psychiatry of mental handicap and joint appointments will occur more frequently, but in every district there is a need for at least one full time Consultant Psychiatrist in Mental Handicap. This will go a long way in changing the attitudes of the laymen and professionals and in re-organising hospitals for the mentally handicapped, with a reduction in the number of beds (and in smaller accommodation, preferably bungalows $4-6$ bedded with single rooms) and developing community homes, some of which, ideally, will have to be run by the NHS.

The job of Psychiatrist in Mental Handicap is extremely interesting, fascinating and challenging but it could be very dull, depressing and thoroughly frustrating depending on what we make of it and how able we are in initiating changes and how successful we are in making others accept these changes.

\section{Windsor Unit}

D. Chakraborti

King's Lynn, Norfolk

\section{Prejudice and mental handicap \\ Dear Sirs}

I was recently shown a copy of Public Service, NALGO's publication for December 1986, in which it was reported of Sir Brian Rix, the Secretary-General of MENCAP, "The mentally handicapped", he declares, "don't need locking up, they don't need drugs or psychiatrists".

Shortly after reading this I was asked urgently to see a mentally handicapped young man who had become agitated and had begun to attack his elderly parents. Under my care at present are a mentally handicapped man who has killed, another who has threatened people with a knife, and a woman who has set fires. On Christmas Day I received a call from a duty social worker anxious about a mentally handicapped man who was enjoying this community care by ordering about his ailing father and mother after having broken most of their crockery.

It is a pity that in mental handicap time and energy appear still to be dissipated on denigrating hospitals, where the vast proportion of patients since 1959 have been informal and not locked away, on sniping at psychiatrists, and perpetuating divisiveness. In practice over the years the difficulty has been attracting psychiatrists to take an interest in mental handicap, not the opposite. In fact the trend away from institutional care for mental handicap has paralleled the growth in the number of psychiatrists in this field and their general philosophy of not hospitalising mentally handicapped people, but developing out-patient and community support services. 